\title{
Research on teaching practice in a Portuguese initial secondary mathematics teacher education program
}

\author{
João Pedro da Ponte, Leonor Santos, Hélia Oliveira, Ana Henriques \\ Instituto de Educação, Universidade de Lisboa \\ Alameda da Universidade \\ 1649-013 Lisboa, Portugal \\ jpponte@ie.ulisboa.pt \\ Tel. +351217943633 \\ Fax +351217933408
}

\begin{abstract}
In teacher education, a key issue is how prospective teachers learn. At the University of Lisbon, based on an inquiry-based approach to mathematics learning, we developed a secondary school mathematics teacher education program, in which a central feature is the elaboration of a final investigative report based on teaching practice. In this paper, our aim is to understand the professional learning opportunities and difficulties recognized by prospective teachers (PT) in their final reports, by addressing the following research questions: (i) What didactical choices do PT mention regarding the approach to teaching, the use of tasks, resources and assessment strategies in their teaching practices? (ii) What transversal elements of teaching practices do they recognize as enabling their professional development? and (iii) What elements of the investigative work do PT refer to as major professional learning outcomes? Using content analysis, we reviewed, coded, and analyzed all 38 reports produced so far in the program. The results suggest that the PT embraced an inquiry-based approach to learning, valuing the role of suitable tasks and of whole class discussions. They also valued reflection and collaboration as practices that support professional development. Prospective teachers also indicated some difficulties and challenges in doing this investigation based on their teaching practice, but even so they tended to regard it a learning opportunity. We conclude that the final report, by its content, structure, and working processes as framed in this teaching education program, supports participants' development as teachers who hold research in positive regard.
\end{abstract}

Key words: Prospective teacher education, Secondary, Mathematics, Teaching Practice; Investigative work.

\section{Introduction}

In a recent article, Cochran-Smith and Villegas (2015) indicate that current research on the preparation of prospective teachers (PT) is driven by two broad questions: the policy question and the learning question. The policy question concerns issues of effectiveness and accountability, related policies, and how institutions react to them. The learning question concerns issues regarding how teacher candidates learn to teach in the 
conditions of the $21^{\text {st }}$ century society and with increasingly diversified pupil groups. In this paper we focus in the learning question in relation to the specific conditions of the University of Lisbon.

In Portugal, the educational system is centralized and the national law sets very specific requirements relating to the education of PT. The preparation of mathematics teachers ${ }^{1}$ is carried out at universities and requires a masters' of teaching degree which includes components similar to those existing in many other countries (Bergsten et al. 2009) concerning mathematics, general education, didactics of mathematics and a period of teaching practice. A specific requirement is that teaching practice must lead to the elaboration of a final report. Such regulations raise issues regarding the specific content of those components and, most especially, the teaching and learning approach to adopt in the masters' program and the nature of the final report.

As Tatto, Lerman and Novotna (2010) recognize, little is known regarding the different ways of framing prospective mathematics teachers learning: "We still lack information regarding how opportunities to learn are organized during those years, and the impact that these diverse opportunities have on mathematics learning and on learning to teach mathematics" (p. 323). In this way, our challenge is to find a response to the "learning question" in the specific conditions of our country, designing a two year teacher education program that prepares teacher candidates for the beginning of the profession, according to the structure officially defined, and taking into account the different factors that influence teacher education (Ponte and Chapman 2016).

In alignment with current curriculum orientations for mathematics teaching, our masters' of teaching program follows an inquiry-based perspective on mathematics learning (Artigue and Blomhøj 2013; Maa $\beta$ and Artigue 2013; NCTM 2014). In such an approach, PT have the opportunity to construct or deepen their knowledge and understanding of mathematics by working, in pairs or small groups, on problems and other challenging tasks in a classroom environment that stresses dialogical communication (Ponte et al. 2015). Taking into account that the pedagogy of the teacher education program must be consistent with the pedagogy for mathematics teaching in schools (Watson and Mason 2007), we also consider how the final report, as required by the official regulations, can be valued by PT as including a small-scale investigation. However, we are aware of the difficulties entailed by framing such a report in this way,

${ }^{1}$ Mathematics teachers teach lower (grades 7-9) and upper secondary school (grades 10-12). 
taking into account the variety of issues involved in promoting an inquiry-based approach to mathematics learning and the conditions in the schools where PT undertake their teaching practice.

The aim of this paper is to understand the professional learning opportunities and difficulties that are recognized by PT in their final reports. We formulate the following research questions: (i) What didactical choices do PT mention regarding the approach to teaching, the use of tasks, resources and assessment strategies in their teaching practices? (ii) What transversal elements of teaching practices do PT recognize as enabling their professional development? and (iii) What elements of the investigative work do PT refer to as major professional learning outcomes?

\section{Prospective teachers' research as part of teacher education programs}

To investigate is a powerful way of constructing knowledge (Ponte 2008). It involves formulating a research question, seeking to document it with previous knowledge on related questions, defining a process to collect data to respond to the proposed question, and seeking to arrive at justified conclusions from such data through a systematic method. In many cases, the deepening and the clarification of the research results depend on their dissemination in the community of reference, subjecting those results to critique and collective reflection (Beillerot 2001). Investigating presupposes reflection, taking into account the different sides of issues, seeking to understand the origin of problems and their meaning according to different perspectives. However, investigating goes beyond reflection, involving deliberate planning, setting up a research goal, and following a methodical process of collecting and analyzing information in order to attain that goal. Scientists carry out academic research, which is a very sophisticated form of research, but many other people, including professionals and pupils, can also conduct research adapted to their needs and goals, provided that they undertake the steps and activities that characterize the research activity (Ponte 2008).

Conducted with commitment, the investigation experience is very intense and has a high transformation and learning potential for the participants. It creates opportunities for developing new knowledge and skills and also for promoting changes in the participants' identity, that is, in their "values, beliefs, habits, norms, dispositions, and in general, ways of being a teacher" (Ponte and Chapman 2016, p. 275). In mathematics education, the arguments that support the inclusion of investigative experiences in the 
preparation of PT are based on this learning potential, especially regarding their future role as mathematics teachers and their understanding of learning environments (Crawford and Adler 1996). Moreover, Krainer (2002) argues that investigation activities develop in PT, abilities that lead them to regard their professional development critically, in addition to the possible contribution of research to their development.

Highlighting the role of research as an educational experience in teacher education yields difficulties at several levels. First, as the education of PT is a process in which the participants have to develop competences in many fields and also their own identity as teachers, the introduction of this activity may imply the weakening of several other teacher education goals (Kitchen and Stevens 2007). Second, PT doing research on their teaching practice requires close supervision and follow-up, which are essential processes in order to avoid the risk of having this experience become a negative one. These processes consume human resources usually scarce in teacher education institutions. Third, carrying out research may be difficult to integrate into the official requirements or in the framework of the institution and, in addition, it requires the allocation of time and working conditions for schools, cooperating teachers, and pupils that may be difficult to achieve. And fourth, PT often lack the necessary maturity, not only in knowledge of mathematics and didactics of mathematics, but also regarding their personal and social development.

In several institutions there is a requirement of substantial investigative work within the teacher education program. In some cases, this is carried out in an actionresearch perspective (Kizilaslan and Leutwyler 2012), and, in other cases, it is done in an interpretative perspective, carried out in the frame of professional practice (Ponte 2008). For example, Peter-Koop (2001) reports that the introduction of research as an element of the preparation of PT is a strong trend in several German universities. She describes the case of her university in which these research studies aim to develop in elementary school PT "diagnostic abilities on the basis of mathematical subject knowledge as well as knowledge about the social-interactive dimension of mathematics learning" (p. 76). Therefore, they participate in qualitative research studies in progress at the university, assuming responsibility for some sub questions, and they work together with other colleagues. According to the author, the PT tend to express an initial feeling of frustration with the quality of the data collected, which changes as the 
analysis of data progresses and they recognize that there is significant richness in pupils' achievement. In her perspective, PT learn at several levels:

\begin{abstract}
The student teachers learn about an important aspect of elementary mathematics (...) Their statements demonstrate that the student teachers learn to 'listen' to pupils with respect to their thinking and (...) their collaborative problem solving strategies (...) Finally, research designs that are based on the interpretative approach can enable the involved student teachers to learn about themselves as teachers. During the interpretation stages most student teachers used the opportunity to critically reflect on their individual classroom behavior, interaction and instruction skills. (pp. 77-78)
\end{abstract}

Stehlíková and Jirotková (2003) describe the case of Charles University, in Prague, where elementary and secondary school PT have to write a diploma thesis. This work is oriented to the study of the thinking processes of the pupils and of the teacher in the class. According to these authors, this approach has several important features, including an extended elaboration period (whose duration may extend up to three years), the experimentation by PT in real educational situations as well as their introspective analysis of events. The authors highlight the mutual influence between the PT and the university supervisor and the involvement of this person in the study of the topic. During the extended elaboration of the diploma thesis there is a continuous change in roles both for the PT and the supervisor: "pupil, teacher, researcher and possibly expert" (pp. 160-161). The authors point to the main factors of success: "First, we were able to offer the pupils tasks early in the course, which they found interesting. Next, we involved them in our research, which stimulated them into doing their own research in the area" (p. 163). They consider distancing to be a fundamental element for developing the capacity to assume the role of researcher, and that this is enhanced by the continuous change of roles.

Nicol and Crespo (2003) carried out a study in a year-long teacher education program for post-baccalaureate students in which, as a final assignment after a teaching practicum of three months, PT are required to describe in writing their cases of teaching and learning based on their experiences. The authors assume that adequate connections between knowledge, practice, and identity in a teacher education program may provide possibilities for participants to develop new identities as mathematics teachers. The results showed that elementary school PT developed a relationship with mathematics and with mathematics teaching "that included the inclination to seek conceptual 
understanding and pursue a stance of inquiry" (p. 373), being able to learn in and from practice.

Towers (2010) describes a two year teacher education program based "on inquirybased, learner-focused and field-oriented principles and practices" (p. 247). In a final seminar, PT carry out a research project that leads them to revisit a school that they attended before, now in the role of researchers, to study teaching and learning issues in context in a deeper way. In her study, in the final seminar, PT carry out mathematical tasks that lead them to engage in inquiry mathematics learning and to make contact with current research on mathematics teaching addressing this perspective. The fact that the program values an inquiry-based approach for mathematics teaching at the same time that it follows a similar orientation for teacher education leads many PT to embrace this perspective. She notes, however, that strong inquiry-based teaching constitutes a very complex practice, with plenty of subtle issues, that many PT may think is beyond their reach, "feeling as though they have no stable ground on which to stand, no confidence in the validity of their approach, and no authority to teach" (p. 260), in contrast to a more conventional teaching approach, which enables them to have a sense of control and predictability. The case presented in her study shows the possibility of attaining the set goals, provided that the necessary conditions are met.

The ICMI Study 15 addressed the professional education and development of mathematics teachers and several chapters of the resulting book (Even and Ball 2009) concern pre-service teacher education. However, none of these chapters addresses the role of investigative work in PT education, which leads us to think that despite the experiences described above this is a seldom studied approach in the preparation of future mathematics teachers.

\section{Background of research: The teacher education program}

According to official regulations, the preparation of mathematics PT for lower and upper secondary levels in Portugal is carried out in a two year masters' program organized in four domains-Mathematics, Didactics of Mathematics, General Education and Practical Preparation - assuming the requirement of strong preparation in mathematics, didactics and education, and the relevance of professional practice in articulation with the other three domains. To this general orientation, the University of Lisbon adds the concern of promoting a reflective and critical stance in PT and in the 
value of developing investigative work in the context of teaching practice as a key learning activity in teacher education.

To be admitted into the program, candidates must have a minimum of 120 ECTS $^{2}$ of university mathematics. This preparation is reinforced with three mathematics courses (18 ECTS) taught by mathematicians in the Faculty of Sciences. The preparation in Didactics of Mathematics (30 ECTS) is the main responsibility of mathematics educators (including the authors) and concerns topics such as mathematics curriculum aims and orientations, teaching strategies, classroom dynamics, tasks and learning resources, as well the teaching of specific mathematics topics (numbers, algebra, geometry, probability and statistics) and pupils' associated difficulties, taking into account research-based knowledge. General Education courses (24 ECTS) include issues such as school and society, school as an educational organization, learning, curriculum and assessment, inclusive education and pupils with special needs. Finally, Practical Preparation (48 ECTS) spans all four semesters, with an emphasis on the last one, in which PT undertake supervised teaching practice in a school. This extended presence in schools generates many opportunities for PT to merge theory and practice, mobilizing and assigning meaning to knowledge from different domains, as well as to develop a reflective and critical stance towards teaching practice.

In the first year ( $1^{\text {st }}$ and $2^{\text {nd }}$ semesters), the PT Practical Preparation begins with PT observing lessons and acknowledging different professional roles of mathematics teachers. The aim is that they recognize the school reality and reflect about it as they learn and use research methods such as observation and interviews. In the $3^{\text {rd }}$ semester, the PT begin their supervised teaching practice in a school, assuming gradually the role of the teacher in one or more classes of the cooperating teacher. They also begin planning their investigative work to carry out in the $4^{\text {th }}$ semester, preparing a teaching unit and defining a research problematic as the main focus of the final report. This research problematic must take into account the teaching of a mathematical topic or the promotion of a capacity, as well as the characteristics of the pupils in the class. This work is supervised by a mathematics educator who follows the PT practice during the $3^{\text {rd }}$ and $4^{\text {th }}$ semesters and also by a mathematician. In the $3^{\text {rd }}$ semester there are several seminars in which the aims, structure and content of the investigative project are

\footnotetext{
${ }^{2}$ European measure of university credits. A semester has 30 ECTS.
} 
discussed in detail. As an important step in developing these projects, the PT present and discuss them in a seminar at the end of the semester.

The $4^{\text {th }}$ semester is fully devoted to supervised teaching practice and work on the final report which is presented and discussed by a committee of university teachers involved in the program. We consider that to require the PT to produce an academic research study would be inappropriate, since what they need is a preparation that supports their introduction into the teaching profession as mathematics teachers and not a preparation as researchers. Therefore, the option we adopted was to value the report on the supervised teaching practice as including two intertwined components, the description of a teaching unit and a small-scale investigation. The PT plan and teach a teaching unit in a class, involving at least 10 lessons, and undertake the investigative work in that context.

During all four semesters, Practical Preparation and Didactics of Mathematics are strongly related, with the teachers of both domains working in close collaboration, jointly articulating contents and planning activities. Thus, the preparation of PT in Didactics of Mathematics provides them with foundations for their supervised teaching intervention and this, in turn, equips them with didactical knowledge.

Cooperating teachers provide continuous support in guiding the PT (who usually work with a partner) in all dimensions of teaching practice. Usually, there are 3 or 4 cooperating teachers each year, both male and female, with significant teaching experience (more than 15 years). They are selected by the university and, besides the training as mathematics teachers at the bachelor's degree level, most of them have specialized training (at the master's or doctoral level) in the field of didactics of mathematics, obtained at our Institute. The Practical Preparation of the PT calls for a joint and continuing dialogue between the university supervisors and the cooperating teachers, which is manifested in quite stable working teams, seeking to support the PT in developing knowledge and capacities to face the challenges they meet along the way, and will later meet as mathematics teachers.

\section{Research methods}

In this study we analyze all the 38 reports made by the PT ( 31 female and 7 male) at the University of Lisbon, in the six year period since the beginning of the program (from 2010 to 2015). The PT age range is 22 to 52 years, with a median of 24 years when they 
completed the report. The majority of PT (91\%) completed a degree in mathematics in their undergraduate education. Most of them (79\%) had no previous experience in teaching mathematics in elementary or secondary schools. ${ }^{3}$

The structure and expected content of the reports are set out in university guidelines, indicating that this must include: (i) Introduction, presenting and explaining the context and content of the teaching intervention and the aims and questions of the investigative component; (ii) Curriculum and educational framework, presenting the main ideas of a review of curriculum and research literature; (iii) Teaching unit, describing the context in which the teaching intervention occurs, the teaching approach, the taught lessons (including tasks, resources and assessment strategies) and the methods concerning data collection and analysis; (iv) Analysis of data, analysing data collected in the classroom and eventually elsewhere according to the aims and questions of the study; and (v) Conclusions, presenting a response to the initial aims and questions and a final reflection on the work carried out.

We downloaded all reports from the public website of the University of Lisbon (http://repositorio.ul.pt/). With the exception of section ii), all parts of the 38 reports were analysed through content analysis (Bardin 2003). Using pre-established categories, following a deductive approach, we performed a systematic reading process, seeking to characterize the school level, mathematical themes and mathematical capacities targeted by the PT (the results are reported in Section 5). To identify the didactical choices made by the PT, we also used four pre-established categories according to the aforementioned report guidelines for the Teaching unit: teaching approach, type of tasks, teaching resources, and assessment strategies (the results are reported in Section 6.1).

Finally, regarding the elements that the PT recognize as enabling their professional learning and the difficulties that they faced concerning transversal issues in teaching practice and in doing the investigative work, we could not anticipate what aspects they would refer to because they were not explicitly asked to write about their learning opportunities or the difficulties that they faced in the process that contributed to their final reports. Therefore, we followed an inductive approach, defining categories from themes that appeared strongly in the data (see coding scheme in the Appendix) as explained by Erickson (1986). Other possible categories regarding these two dimensions that were not so present in the data were not considered in this analysis. Hence, for these

\footnotetext{
${ }^{3}$ The PT who had teaching experience taught mathematics as "provisional teachers" in temporary jobs.
} 
two dimensions, the categories are constructed from the data, informed by our knowledge about teaching practice and doing an investigation, as teacher educators (the results are reported in Sections 6.2 and 6.3).

The reports were coded independently by three experienced researchers (among the authors), each one focusing on a dimension of analysis from the three research questions, assuming whole sentences of the reports as units of analysis. After a first codification of all the material, each researcher selected a set of quotations that were discussed by the four authors, seeking to identify the adequacy of their coding and verifying that they met quality criteria of content analysis, such as exclusivity, homogeneity and pertinence (Bardin 2003). When there were divergent interpretations or doubts concerning a category or codification, the necessary adjustments were made, and the final coding scheme was produced and used to analyse all transcriptions previously selected. An interrater reliability study involving an independent rater for a sample of data covering all research questions showed $91 \%$ of agreement in this coding process, which is considered satisfactory.

In the results section, and for each dimension of the analysis, we present quantitative results and illustrate our interpretations with quotations from prospective teachers' reports (mentioned as PTi). The selected quotations express the general idea associated with the respective category, in some cases providing evidence of certain learning opportunities recognized by the PT, and in other cases of the difficulties that they faced. In some instances more than one quotation is presented for a single aspect in order to illustrate complementary issues.

\section{Context and focus of the reports}

Usually, the class for supervised teaching practice is chosen by the cooperating teacher. The distribution of the 38 reports (Table 1) shows that supervised teaching practice mostly takes place at the lower secondary level.

Table 1. Distribution of reports by school level

\begin{tabular}{cc}
\hline School level & Reports \\
\hline Lower secondary (pupils 12-14 years) & $26(68 \%)$ \\
Upper secondary (pupils 15-17 years) & $12(32 \%)$
\end{tabular}


The PT and the cooperating teacher choose the teaching unit taking into account the mathematics school yearly planning and the foreseen period for the teaching intervention. The PT must make their intervention in the first half of the $4^{\text {th }}$ semester in order to be able to write the report by the end of this semester. Thus, there is a concentration of the themes of the reports on algebra, followed by geometry (Table 2).

Table 2. Distribution of reports by mathematical theme

\begin{tabular}{lccc}
\hline \multirow{2}{*}{ Mathematical theme } & \multicolumn{3}{c}{ Number of reports } \\
\cline { 2 - 4 } & $\begin{array}{c}\text { Lower secondary } \\
(\mathrm{n}=26)\end{array}$ & $\begin{array}{c}\text { Upper secondary } \\
(\mathrm{n}=12)\end{array}$ & $\begin{array}{c}\text { Total } \\
(\mathrm{n}=38)\end{array}$ \\
\hline Numbers and operations & $1(4 \%)$ & - & $1(3 \%)$ \\
Algebra & $16(62 \%)$ & $11(92 \%)$ & $27(71 \%)$ \\
Geometry & $7(27 \%)$ & $1(8 \%)$ & $8(21 \%)$ \\
$\begin{array}{l}\text { Data analysis and } \\
\text { probability }\end{array}$ & $2(8 \%)$ & - & $2(5 \%)$ \\
\hline
\end{tabular}

Most reports focus on pupils' learning, generally seeking to study their difficulties and errors on a given mathematical topic: "This study aims to understand what difficulties grade 7 pupils show when working on situations involving algebraic thinking, in particular, what difficulties and errors they make in solving $1^{\text {st }}$ degree equations" (PT3, 2012, p. 1). However, pupils' mathematical capacities indicated in the national curriculum were also important objects of study and are mentioned in 27 out of the $38(71 \%)$ reports (Table 3 ).

Table 3. Reports addressing mathematical capacities as the object of study

\begin{tabular}{lc}
\hline \multicolumn{1}{c}{ Mathematical capacities } & $\begin{array}{c}\text { Number of reports } \\
(\mathrm{n}=27)\end{array}$ \\
\hline Problem solving & $11(41 \%)$ \\
Mathematical reasoning & $6(22 \%)$ \\
Representations & $6(22 \%)$ \\
Mathematical communication & $2(7 \%)$ \\
Connections & $2(7 \%)$ \\
\hline
\end{tabular}


Problem solving is the mathematical capacity that is more often taken as an object of study. It appears paired with several mathematical themes and is analysed from different perspectives, such as identifying pupils' representations, strategies and difficulties in solving problems:

This study aims, in general, to understand how the pupils interpret geometric problems, the strategies that they develop, how they use their knowledge and the difficulties they show in this mathematical transversal capacity. (PT28, 2011, p. 2)

The aim of this study is to analyse if pupils understand and know how to use different types of representations in solving problematic situations involving $1^{\text {st }}$ grade inequalities. (PT10, 2013, p. 4)

In the reports that focus on mathematical reasoning, there are references to mathematical argumentation, formulating and testing conjectures, and reasoning in algebra and geometry:

i) How do pupils formulate, test and justify their conjectures in solving exploration/investigative tasks? ii) How do pupils base their claims using concepts and geometrical properties? iii) What difficulties do pupils show regarding mathematical reasoning? (PT24, 2011, p. 2)

The main objective of this investigative study is to understand grade 8 pupils' learning in solving literal equations and algebraic expressions, particularly how they develop algebraic thinking in this context, including symbol and variable sense. (PT26, 2012, p. 4)

The PT that chose communication and mathematical representations as objects of study focused on the understanding of pupils' language and mathematical representations or addressed pupils' difficulties:

(i) What is the level of rigor of mathematical language used by grade 10 pupils in written communication when they work in groups? Do they use symbolic mathematical terminology and formal vocabulary? What are their main difficulties? (ii) How do pupils produce written explanations when working in groups? What are their main difficulties? (iii) What kind of representations - algebraic or graphic - do pupils more often use? What are the main difficulties associated with algebraic and graphical approaches? (PT18, 2015, pp. 2-3) 
Finally, there are two reports in which the object of study is not pupils' learning but the role of the PT in teaching a mathematical topic. One of them, for example, indicates: "[I seek to] understand the nature of my discourse as a teacher in the mathematics classroom, when working on the topic of literal equations" (PT6, 2010, p. $5)$.

\section{Findings}

\subsection{Prospective teachers' didactical choices}

All PT indicated the value of an inquiry-based approach to mathematics teaching and showed willingness to follow current mathematics curriculum orientations. In particular, they tended to highlight the importance of pupils' work on tasks and of classroom interactions to support mathematics learning. In their cooperating teachers' classes the pupils worked mostly in pairs, and the same occurred in the PT classes too. They also indicated to value whole class discussions as important learning moments both for the pupils and for themselves:

The discussion of the tasks was for me one of the more instructive aspects of the class. I understood how important this moment is for pupils' learning. (PT16, 2014, p. 105)

The discussions with the whole class were also important learning moments for me (...) I understood the role of the teacher in the discussion of tasks with the whole class. (PT1, 2013, p. 112)

In their reports, the PT referred to the importance of using several types of tasks, as shown in Table 4.

Table 4. Types of tasks indicated in the reports

\begin{tabular}{lccc}
\hline \multirow{2}{*}{ Types of tasks } & \multicolumn{3}{c}{ Number of reports } \\
\cline { 2 - 4 } & $\begin{array}{c}\text { Lower secondary } \\
(\mathrm{n}=26)\end{array}$ & $\begin{array}{c}\text { Upper secondary } \\
(\mathrm{n}=12)\end{array}$ & $\begin{array}{c}\text { Total } \\
(\mathrm{n}=38)\end{array}$ \\
\hline Exercises & $24(92 \%)$ & $11(92 \%)$ & $35(92 \%)$ \\
Problems & $23(84 \%)$ & $12(100 \%)$ & $35(92 \%)$ \\
Exploratory tasks & $19(73 \%)$ & $10(83 \%)$ & $29(76 \%)$ \\
Investigations & $4(15 \%)$ & $5(42 \%)$ & $9(24 \%)$ \\
\hline
\end{tabular}


In both lower and upper secondary school levels, most PT reported that they used exercises and problems in their teaching practice (Table 4). Exploratory tasks were also highly mentioned. Many of them acknowledged the need to select each type of task according to the learning aims for the class, and in the reports we find references to exercises to consolidate knowledge and to exploratory tasks and problems to introduce new topics and to challenge pupils:

I also tried to combine different types of tasks (pupils have different ways of learning) (...) (1) exploratory tasks (...) to introduce new concepts (...) (2) problems with more or less mathematical challenge (...) (3) exercises from the textbook that promote algebraic manipulation to develop skills in calculating the limits and derivatives, among others. (PT8, 2015, p. 53)

However, for example, a PT recognized that designing tasks and managing time in solving them was a difficulty that she faced in her teaching experience:

It is not easy to think and to design tasks that may be challenging for the pupils and at the same time allow one to attain the established goals. A difficulty that appeared during the study was to manage the time to solve each task. (PT21, 2010, p. 89)

To support classroom work, the PT said that they used diverse teaching resources (Table 5). Almost all PT mentioned the textbook as a resource to support teaching and learning, using it to propose tasks in the classroom or to assign homework. The blackboard is another teaching resource widely used for many purposes, including a desire to support whole class discussions: "I planned to create, in all classes, moments in which pupils go to the blackboard to explain their solutions to their colleagues" (PT5, 2015, p. 32).

Table 5. Teaching resources indicated in the reports

\begin{tabular}{lccc}
\hline \multirow{2}{*}{ Teaching resources } & \multicolumn{3}{c}{ Number of reports } \\
\cline { 2 - 4 } & $\begin{array}{c}\text { Lower } \\
\text { secondary } \\
(\mathrm{n}=26)\end{array}$ & $\begin{array}{c}\text { Upper } \\
\text { secondary } \\
(\mathrm{n}=12)\end{array}$ & Total \\
$(\mathrm{n}=38)$
\end{tabular}


Technology for pupils' work

Technology was also mentioned considerably by PT (Table 5), both to be used by them and by their pupils. In the first case, the aim was mostly to project pupils' solutions to support whole class discussion or to illustrate key mathematical concepts, especially at the upper secondary level. They also mentioned that pupils used technology, such as Excel, dynamic geometry and graphing software, graphic calculators, and applets especially designed to support learning of mathematics concepts. We find more references on technology at upper secondary level, which is not surprising because the Portuguese mathematical curriculum for this level establishes the use of the graphic calculator as compulsory.

Finally, the PT also mentioned different assessment strategies to regulate pupils' learning or teacher practice and to verify pupils' learning (Table 6).

Table 6. Assessment strategies indicated in the reports

\begin{tabular}{|c|c|c|c|c|}
\hline \multirow[b]{2}{*}{$\begin{array}{c}\text { Modes of } \\
\text { assessment }\end{array}$} & \multirow[b]{2}{*}{ Assessment strategies } & \multicolumn{3}{|c|}{ Number of reports } \\
\hline & & $\begin{array}{c}\text { Lower } \\
\text { secondary } \\
(n=26)\end{array}$ & $\begin{array}{c}\text { Upper } \\
\text { secondary } \\
(\mathrm{n}=12)\end{array}$ & $\begin{array}{l}\text { Total } \\
(\mathrm{n}=38)\end{array}$ \\
\hline \multirow{5}{*}{$\begin{array}{l}\text { Formative } \\
\text { assessment }\end{array}$} & Observation of pupils' work & $17(65 \%)$ & $11(92 \%)$ & $28(74 \%)$ \\
\hline & Oral questioning & $4(15 \%)$ & $4(33 \%)$ & $8(21 \%)$ \\
\hline & Pupils' written worksheets & $19(73 \%)$ & $4(33 \%)$ & $23(61 \%)$ \\
\hline & Quizzes & $4(15 \%)$ & $4(33 \%)$ & $8(21 \%)$ \\
\hline & Homework & $19(73 \%)$ & $8(67 \%)$ & $27(71 \%)$ \\
\hline \multirow{3}{*}{$\begin{array}{l}\text { Summative } \\
\text { assessment }\end{array}$} & Written tests & $10(38 \%)$ & $6(50 \%)$ & $26(68 \%)$ \\
\hline & Reports & $1(4 \%)$ & $2(17 \%)$ & $3(8 \%)$ \\
\hline & Oral presentations & $1(4 \%)$ & $0(0 \%)$ & $1(3 \%)$ \\
\hline
\end{tabular}

To regulate pupils' learning or teacher's practice, many PT reported that they used observation of pupils' work in the classroom (Table 6). At lower secondary level, the analysis of pupils' written worksheets was also a frequent strategy. There were also some references to oral questioning and quizzes. Homework was very common in both school levels, representing an opportunity for the pupils to consolidate their knowledge 
and for the teacher to know pupils' difficulties and, consequently, to regulate teaching practice:

I notice that, for pupils, to do homework helps them to consolidate learning. (PT12, 2015, p. 35)

Analysing the homework, I found some errors, in particular concerning the notion of vertical angles. So I decided that it was important to give some oral feedback to pupils in order to clarify some existing confusion. (PT24, 2011, p. 45)

To verify pupils' learning, the PT used written tests or constructed questions to include later on a test. A few used reports and only one used oral presentations.

In summary, the analysis of the reports shows that the PT, while recognizing some difficulties, seem to have appropriated central aspects of an inquiry-based approach to mathematics teaching, such as conducting whole class discussions, emphasizing problem solving and explorations, using technology and other resources, as well as enacting several assessment practices to regulate and verify pupils' learning.

\subsection{Prospective teachers' perspectives on transversal issues}

In one way or another, all the PT recognized the formative process of constructing a report as an enriching experience for their learning, indicating contributions that they considered significant to their professional development. In their reports, three key elements of the teaching profession stand out, although with different emphasis: appreciation of the ways of preparing instructional activities, reflection on practice, and collaborative work (Table 7).

Table 7. Transversal elements of teaching practices highlighted in the reports

\begin{tabular}{|c|c|c|c|}
\hline \multirow[b]{2}{*}{$\begin{array}{l}\text { Transversal components } \\
\text { of teaching practices }\end{array}$} & \multicolumn{3}{|c|}{ Number of reports } \\
\hline & $\begin{array}{l}\text { Lower secondary } \\
\qquad(\mathrm{n}=26)\end{array}$ & $\begin{array}{l}\text { Upper secondary } \\
\qquad(\mathrm{n}=12)\end{array}$ & $\begin{array}{c}\text { Total } \\
(\mathrm{n}=38)\end{array}$ \\
\hline Planning & $14(54 \%)$ & $6(50 \%)$ & $20(53 \%)$ \\
\hline Reflection & $22(85 \%)$ & $8(67 \%)$ & $30(79 \%)$ \\
\hline Collaborative work & $13(50 \%)$ & $8(67 \%)$ & $21(55 \%)$ \\
\hline
\end{tabular}


As Table 7 indicates, about half of the PT recognized that lesson planning is important for teaching. Albeit mentioning difficulties, they acknowledged that planning supports organizing the work according to the formative purposes of mathematics education and to making permanent adjustments according to the pupils' needs and interests. They also emphasized the role of lesson plans particularly in facing unexpected situations in the classroom, which they regarded as a common situation:

Lesson planning is (...) a strong support to the work carried out in class. In particular, it helped me to focus on the purpose of teaching, anticipating various possible scenarios of action and decisions. (PT11, 2014, p. 117)

Lesson planning was important since it guides us in managing the time in each moment of the lesson, providing some important notes for the teacher to guide the class, whether regarding pupils' autonomous work or whole class discussions. It also helps us [to deal with] possible unforeseen situations occurring in class and so the teacher feels more secure and confident. (PT25, 2012, p. 80)

Reflection is an element of the teaching practices also widely mentioned in the reports (Table 7). Some PT mentioned that learning to act as a reflective practitioner means to be able to analyze their own professional work supporting the improvement of their teaching practices: "Taking into account that the goal for all teachers is to make their classes a place of effective knowledge construction, it becomes essential that all professionals 'stop' and reflect on their own practice” (PT23, 2014, p. 100).

Reflection is mentioned by the PT as enabling professional development: "The learning that results from planning and teaching is indisputable, but it was reflection that allowed me to evolve more (...) I see it as a step forward to a consistent professional practice" (PT15, 2013, p. 133). This is probably a consequence of the reflection that they are required to make at the end of each class, guided by their supervisors and cooperating teachers. Therefore, they tended to recognize reflection as required in order to improve classroom practice. For example, a prospective teacher indicated that "the moment of reflection is to ascertain possible improvements to make in future interventions. If we are not able to identify them it is very unlikely that we learnt from the experience" (PT19, 2012, p. 81).

Some reports show how the PT were led to formulate conjectures or explanatory hypotheses and to reflect on what they might change in their practice to support pupils' mathematical thinking: 
Given some data from the study, it seems to me that the hierarchical classification of the rectangle was better accepted [by the pupils] than the hierarchical classification of the rhombus. This attitude may be associated with the similar visual appearance of the square and rectangle. This was mentioned by Alberto in one of the interviews (...), justifying why the square belongs to the family of rectangles and therefore highlighting the influence of visualization. (PT15, p. 112)

Finally, Table 7 also shows that collaborative work was also highly valued by the PT in their reports. The construction of a report is a complex activity that leads them to experience some tensions and conflicts. Therefore, they regarded the support team involving the supervisor and the cooperating teacher and the collaborative work with the master's partner as essential to help them evolve as teachers and to improve their practice. The PT valued this joint work, highlighting for example the support that they received in lesson planning: "The support of the supervisor and the cooperating teacher was essential to be able to develop appropriate lesson plans for the learning objectives and for that specific class" (PT27, 2014, p. 125). Most PT also stressed the contribution of working together with the supervisor, the cooperating teacher and the partner in post class discussions to develop their ability to reflect on and to improve their practices:

A very positive aspect of the experience, and I think that it will be reflected in my future practice, was the discussions of lessons, after they occurred, with my supervisors, the cooperating teacher and my master's partner (...). These discussions also helped me (...) to think about what I could improve. (PT16, 2014, p. 105)

At the end of the formative process, several PT recognized the importance of the support structure and collaborative work and claimed that it changed their perspectives:

None of this would be possible without the precious help of my cooperating teacher, partner and supervisor, because with them I realized how important it is to share experiences and to reflect together. (PT17, 2014, p. 78)

Until I attended the master's course, I was quite reluctant to [undertake collaborative] practice, preferring to work by myself (...) I had to change my stance which was extremely positive. Sharing ideas makes the work more challenging and enriches it a lot. As a person, I learned to be more tolerant, to accept other opinions and to realize that I'm not always right. I can say that I finally realized the importance of working together and I think teachers would benefit if they relied more on collaborative work. (PT5, 2015, p. 145) 
Thus, the reflections seem to contribute to the PT coming to realize the need of careful work in planning exploratory activities to deal with unforeseen situations that often arise in the classroom. They also valued lesson planning, taking into account pupils' characteristics to set clear aims for the lessons and anticipate their strategies. The support team involving the supervisor and the cooperating teacher, and the collaborative work with the partner PT, appeared to be a productive context for supporting PT learning, giving them opportunities to improve several aspects of teaching practice and their development as reflexive practitioners. The results lead us to infer that, at the end of the teacher education process, the PT manifested the recognition of the ability to reflect on their own teaching as a specific aspect of teachers' professional development.

\subsection{The role of the investigative work in prospective teachers' learning}

The investigative work assigned to the PT challenged them to assume a new role as researchers, something that they were not expecting when they began the teacher education program. However, many reports show that the PT recognized important outcomes from that work (Table 8).

Table 8. Elements of the investigative work highlighted in the reports

\begin{tabular}{lccc}
\hline \multirow{2}{*}{ Highlighted components } & \multicolumn{3}{c}{ Number of reports } \\
\cline { 2 - 4 } & $\begin{array}{c}\text { Lower secondary } \\
(\mathrm{n}=26)\end{array}$ & $\begin{array}{c}\text { Upper secondary } \\
(\mathrm{n}=12)\end{array}$ & $\begin{array}{c}\text { Total } \\
(\mathrm{n}=38)\end{array}$ \\
\hline Literature review & $12(46 \%)$ & $6(50 \%)$ & $18(47 \%)$ \\
Data collection & $14(53 \%)$ & $5(42 \%)$ & $19(50 \%)$ \\
Data analysis & $18(69 \%)$ & $5(42 \%)$ & $23(61 \%)$ \\
$\begin{array}{l}\text { Reflection about the } \\
\text { investigative work }\end{array}$ & $19(73 \%)$ & $9(75 \%)$ & $28(74 \%)$ \\
\hline
\end{tabular}

The first aspect considered by the PT as one of the major learning outcomes was the role of the literature review, mentioned by almost half of them (Table 8). They commented on the opportunity to get acquainted with research carried out on the topic of their teaching unit as they reviewed literature to support its preparation and the data analysis process. Besides an opportunity to deepen their knowledge about the teaching 
and learning of the topic, some of them regarded this as something that might have an impact in their future professional development:

The review of literature carried out previous to the lessons helped me to develop a "fresh look" at the strategies and difficulties that were investigated by others and therefore facilitated the adaptation and improvement of the tasks, as well as [allowed me] to be prepared for pupils' eventual errors and difficulties in their work. (PT9, 2011, p. 76)

I also learnt the importance that research may have on my future profession. It is very important to seek what the research has already produced in order to have a deep and broad perception of teaching and learning problems in mathematics and how we can do our job better. (PT17, 2014, p. 78)

Some PT mentioned difficulties in producing the curricular and didactical framework for the study, namely when the research on the selected topic was scarce: "one of the initial limitations of this study was to find references that would allow an indepth study on trigonometry of the right triangle" (PT20, 2010, p. 104). There were also explicit references to the difficulty of establishing a framework for data analysis based on the reviewed literature: "A major difficulty was to match the literature and the interview data" (PT5, 2011, p. 93). Even though many PT did not mention their appreciation of the role of the literature review, their reports show that most of them put a lot of effort into such a review and used it to develop the analysis and the reflection of the results.

Half of the PT highlighted that they learned to plan and use research methods to investigate issues and to reflect on the specific opportunities provided by these activities (Table 8). In their studies, the main methods that they used were classroom observation, collecting pupils' written productions, and interviewing pupils. Concerning observation, for instance, some PT attributed great value to field notes and research journals not only for collecting data but also to facilitate reflection on their teaching approaches. In their view, such activities, in some cases, instigated changes in their practice:

Field notes induced changes in the pedagogical strategies that accompanied the development of the study and were very useful for the reflections that followed the teaching period. (PT8, 2015, p. 76)

The research journal allows me to collect data in a natural way and in addition helped me to have a progressive and continuous view of the work carried out and to reflect on the study along its course. (PT30, 2015, p.75) 
Some PT also underlined the important role of audio-recording pupils' interactions as they worked in pairs. These recordings contributed not only to leading PT to give meaning to pupils' written productions but also to provoking their reflection on their practice. For instance, one of them mentioned that the detailed analysis of an episode that occurred with one pair of pupils led her to question the problem that she proposed in the lesson:

I did not foresee that this question might arise among pupils, which leads me to think that there is a weakness in the task statement that caused it. Today, with a proper distance and reflection (...) I know this might be a good question to emerge in the whole class discussion (PT18, 2015, p. $68)$.

Some PT also interviewed a small number of pupils based on mathematical tasks and considered that this led them to a better understanding of their strategies, representations and difficulties:

The interviews were very rich moments because they allowed me to better understand the solving process used by each pupil, the way they used diverse representations to solve problems (...) and also to better understand their difficulties. (PT4, 2011, p. 94)

As one should expect, some PT mentioned difficulties associated with the data collection process in their investigative work, namely, when interviewing pupils: "The interviews were a challenge for me. Although sometimes I induced pupils to meet my expectations for the answers, I feel that I have improved throughout each interview" (PT11, 2014, p. 117).

Most PT highlighted the importance of analyzing the data related to their pupils' work (Table 8), as this helped them to get a deeper knowledge about pupils' learning and thinking processes as well as about the difficulties that they faced during the teaching unit. Some of them foresaw that this reflective process would have an impact in their professional practice:

Data analysis became a fundamental part of this work, leading me to discover how pupils effectively learned the concepts and used them to solve tasks. Also (...) I became aware of their difficulties and this led me to reflect on the possibility of improving my professional practice. (PT5, 2015, pp. 120-121) 
Not surprisingly, some PT also mentioned difficulties that they felt in analyzing data, mainly due to the large amount of information gathered: "Data analysis was one of the hardest tasks to carry out, mainly because of the difficulty in selecting the most relevant data, given the amount of collected data" (PT30, 2015, p. 120).

Most PT associated the reflection on the results of the investigative work with professional learning (Table 8): "This study allowed me to reflect on my practice, both to understand pupils' mathematical reasoning [through data analysis] and how to develop it, and to [focus] on aspects that I still have to work on to foster the pupils' learning" (PT30, 2011, p. 85). In several reports, reflection was closely associated with the nature of the investigative work carried out, articulating knowledge and practice. This is an aspect to which these PT tended to attach great importance because, as one of them said, "with teaching experience, we can make the mistake of failing to look at pupils' productions in an interrogative way" (PT2, 2011, p. 27).

Assuming a double role of teacher and researcher is expected to represent a challenge for PT. Some of them explicitly mentioned the difficulties that they faced in integrating their teaching and research activities in the classroom: "[It was] extremely challenging in terms of the multiplicity of roles that the teacher has to play simultaneously with the observation" (PT27, 2014, p. 72). As one would also expect, some PT pointed out the limited time that they had to develop their study as one of the major constraints to their work: "During this study, a difficulty that I felt was the limited time I had to do it" (PT13, 2010, p. 110).

A result that emerges from the reports is that, for many PT, assuming the double role of teacher and researcher encouraged them to reflect on their teaching practice and gave them the opportunity to get a better understanding of their pupils' learning and thinking process. Some of them recognized the importance of using different research methods and of carrying out data analysis to enrich their reflections, beginning to regard this role as part of teacher's practice. These examples lead us to infer that the investigative activity that they carried out promoted a link between the elements inherent in the investigative work provided by doing the report and their teaching competence.

\section{Discussion and conclusion}


In several countries, prospective mathematics teacher education corresponds to a master's degree involving a substantial product such as a thesis, project, or report. Such regulation of teacher education is also established in Portugal, setting us the question of the nature of the master's degree final report. There are different ways of framing this work, as the studies of Peter-Koop (2001), Stehlíková and Jirotková (2003) and Towers (2010) show. Each one corresponds to a different response to the "learning problem" posed by Cochran-Smith and Villegas (2015).

In a way similar to that described by Crawford and Adler (1996), in the University of Lisbon teacher education program PT are invited to put into practice and to reflect on new approaches to mathematics teaching and learning. They are also asked to reflect on their views regarding mathematics teaching, the roles of teachers and pupils, the ways pupils learn, and how they learn as mathematics teachers. Their reports suggest that the PT undertook significant learning as teachers, concerning inquiry-based approaches to mathematics teaching (Artigue and Blomhøj 2013), an important aspect of professional expertise (Maaß and Artigue 2013). The PT included in their reports the role of suitable tasks as springboards for developing mathematics ideas, namely emphasizing problem solving and exploratory tasks, the potential of whole class discussions, and the need of using appropriate teaching resources and assessment strategies. Through the reflection that the PT developed in the final report, they recognized important transversal issues in teaching, such as the need for careful planning and the value of reflection. They recognized collaboration as important to support their learning as teachers. However, in interpreting the findings of this study, we must be conscious regarding a possible bias in the PT reports, as they could be led to adjust their discourse to what they identify as most valued in the teacher education program.

Despite this caveat, we consider that framing the report as a small professional investigation has contributed to apprising the PT not only of the knowledge produced by academic research but also of the process of producing it. The PT highlighted the opportunity that the research activity gave them to develop a deeper understanding of and meaning for pupils' thinking processes and difficulties, a result also reported by Peter-Koop (2001) and Stehlíková and Jirotková (2003). This opportunity was created by the demands of the research activity, namely the analysis of pupils' work and interactions, sometimes complemented by interviews with pupils. 
We regard the PT difficulties and struggles as natural elements in the process of preparing and doing this report, and much of their learning occurred as they strove to overcome them. These difficulties were associated both with the teaching practice (for example, designing tasks) and to the investigative work (for example, analyzing data). Being a demanding task, it becomes a positive experience, in part due to the support provided by the structure of the teacher education program. An essential condition for the success of this support structure is the alignment of the cooperating teachers with the orientation of the program, assured by the continuing dialogue with the university supervisors and their stability over time. However, although the work concerning the final report starts at the beginning of the school year, the PT complained about the short time they had to develop it. This aspect is a constraint of our teacher education program that is difficult to overcome unless it spanned a period of more than two years (as in the case reported by Stehlíková and Jirotková 2003).

In summary, the findings point out that the PT recognized the value of the investigative work in their learning. This result aligns well with what is also reported for in-service teachers (Lin and Rowland 2016). As Watson and Mason (2007) suggest, we aim to develop a teacher education program consistent with what we consider important for mathematics teaching practice. In a society with a growing diversity of pupils that demands mathematical success for all (NCTM 2014), we regard the competencies highlighted in our program as more than necessary. However further longitudinal studies that follow-up these teachers as they become professionals may provide additional knowledge about the real value of this teacher education approach.

\section{References}

Formatada: Português (Portugal)

Artigue, M., \& Blomhøj, M. (2013). Conceptualizing inquiry-based education in mathematics. ZDM Mathematics Education, 45, 797-810.

Bardin, L. (2003). L'Analyse de contenu (10 ${ }^{\text {th }}$ ed.). Paris: Presses Universitaires de France.

Beillerot, J. (2001). A "pesquisa": Esboço de uma análise. In M. André (Ed.), O papel da pesquisa na formação e na prática dos professores (pp. 71-90). Campinas: Papirus.

Bergsten, C., Grevholm, B., Favilli, F., Bednarz, N., Proulx, J., Mewborn, D., Johnson, P., Rowland, T., Thwaites, A., Huckstep, P., DeBlois, L., Maheux, J.-F., Chapman, O., Rosu, L. M., Arvold, B., Gellert, U., Krummheuer, G., Skott, J., Garegae, K. G., Chakalisa, P. A., Kadijevich, D., Haapasalo, L., Hvorecky, J., 
Carneiro Abrahão, A., de Carvalho Correa de Oliveira, A. T., Novotná, J., Hofmannová, M., Tirosh, D., \& Tsamir, P. (2009). Learning to teach mathematics: Expanding the role of practicum as an integrated part of a teacher education programme. In R. Even \& D. Ball (Eds.), The professional education and development of teachers of mathematics: The 15 ${ }^{\text {th }}$ ICMI Study (pp. 57-70). New York, NY: Springer.

Cochran-Smith, M., \& Villegas, A.M. (2015). Studying teacher preparation: The questions that drive research. European Educational Research Journal, 14(5), 379-394.

Crawford, K., \& Adler, J. (1996). Teachers as researchers in mathematics education. In A.J. Bishop, K. Clements, C. Keitel, J. Kilpatrick \& C. Laborde (Eds.), International handbook of mathematics education (pp. 1187-1205). Dordrecht: Kluwer.

Erickson, F. (1986). Qualitative methods in research on teaching. In M. C. Wittrock (Ed.), Handbook of research on teaching (pp. 119-161). New York, NY: Macmillan.

Even, R., \& Ball, D. L. (Eds.) (2009). The professional education and development of teachers of mathematics: The 15th ICMI Study. New York, NY: Springer.

Kitchen, J., \& Stevens, D. (2007). Action research in teacher education: Preparing preservice teachers to be adaptive experts. Teaching \& Learning, 4(2), 15-20.

Kizilaslan, I., \& Leutwyler, B. (2012). Pre-service teacher action research: Concept, international trends and implications for teacher education in Turkey. In N. Popov et al. (Eds.), International perspectives on education (pp. 155-162). Sofia: Bulgarian Comparative Education Society.

Krainer, K. (2002). Investigation into practice as a powerful means of promoting (student) teachers' professional growth. In J. Novotná (Ed.), CERME 2: European research in mathematics education (Vol. 1, pp. 281-291). Prague: Univerzita Karlova v Praze, Pedagogická Faculta.

Lin, F-L., \& Rowland, T. (2016). Pre-service and in-service mathematics teachers' knowledge and professional development. In A. Gutiérrez, G. Leder, \& P. Boero Formatada: Português (Portugal) (Eds.), The second handbook in the psychology of mathematics education (pp. 483-520). Rotterdam: Sense.

Maa $\beta$, K., \& Artigue, M. (2013). Implementation of inquiry-based learning in day-today teaching: A synthesis. ZDM Mathematics Education, 45(6), 779-795.

NCTM (2014). Principles to actions: Ensuring mathematical success for all. Reston, VA: Author.

Nicol, C., \& Crespo, S. (2003). Learning in and from practice: Teachers investigate their mathematics teaching. Proceedings of PME, 27(3), 373-380.

Peter-Koop, A. (2001). From "teacher researchers" to "student teacher researchers": Diagnostically enriched didactics. Proceedings of PME, 25(1), 72-79.

Ponte, J.P. (2008). Researching our own practice. In B. Czarnocha (Ed.), Handbook of mathematics teaching research (pp. 19-35). Rzeszów: University of Rzeszów.

Ponte, J.P., \& Chapman, O. (2016). Prospective mathematics teachers' learning and knowledge for teaching. In L. English \& D. Kirshner (Eds.), Handbook of 
international research in mathematics education ( ${ }^{\text {rd }}$ ed., pp. 275-296). New York, NY: Routledge.

Ponte, J.P., Quaresma, M., Mata-Pereira, J., \& Baptista, M. (2015). Exercícios, problemas e explorações: Perspetivas de professoras num estudo de aula. Quadrante, 24(2), 11-134.

Stehlíková, N., \& Jirotková, D. (2003). Process oriented research in pre-service mathematics teachers education: A case of diploma theses. In C. Bergsten \& B. Grevholm (Eds.), Challenges in mathematics education (Proceedings of MADIF 3) (pp. 165-174). Linköping: Swedish Society for Research in Mathematics Education.

Tatto, M.T., Lerman, S., \& Novotna, J. (2010). The organization of the mathematics preparation and development of teachers: A report from the ICMI Study 15. Journal of Mathematics Teacher Education, 13(4), 313-324.

Towers, J. (2010). Learning to teach mathematics through inquiry: A focus on the relationship between describing and enacting inquiry-oriented teaching. Journal of Mathematics Teacher Education, 13(3), 243-263.

Watson, A., \& Mason, J. (2007). Taken-as-shared: A review of common assumptions about mathematical tasks in teacher education. Journal of Mathematics Teacher Education, 10(4), 205-215. 


\section{APPENDIX}

Coding schemes for Transversal components of teaching practice and Elements of the investigative work

\begin{tabular}{ll}
\hline $\begin{array}{l}\text { Transversal components } \\
\text { of teaching practice }\end{array}$ & Description \\
\hline Lesson Planning & $\begin{array}{l}\text { Acknowledges learning outcomes or } \\
\text { difficulties associated with the } \\
\text { development of lesson plans in the } \\
\text { teacher practice. }\end{array}$ \\
& $\begin{array}{l}\text { Acknowledges learning outcomes or } \\
\text { difficulties from oral or written } \\
\text { reflective processes in teacher practice } \\
\text { or in writing the final report. }\end{array}$ \\
& $\begin{array}{l}\text { Acknowledges learning outcomes or } \\
\text { difficulties associated with the } \\
\text { collaborative work carried out with other } \\
\text { colleagues, supervisors or cooperating } \\
\text { teacher. }\end{array}$ \\
\hline
\end{tabular}

Elements of the Description

investigative work

Acknowledges learning outcomes or difficulties in reading or writing the

Literature review literature review in the report and in using it in data analysis, and in the conclusions of the final report.

Acknowledges learning outcomes or difficulties in planning, and using

Data collection research methods in the investigative work.

Acknowledges learning outcomes or Data analysis difficulties in data analysis in the investigative work.

Reflection in the Values the role of the investigative work investigative work in promoting reflection. 